\title{
A TUTELA DE BENS JURÍDICOS TRANSINDIVIDUAIS E OS LIMITES ÀS INVESTIGAÇÕ̃ES INTERNAS DOS PROGRAMAS DE COMPLIANCE
}

THE PROTECTION OF TRANSINDIVIDUAL LEGAL RIGHTS AND LIMITS TO INTERNAL INVESTIGATIONS IN COMPLIANCE PROGRAMS 


\title{
A TUTELA DE BENS JURÍDICOS TRANSINDIVIDUAIS E OS LIMITES ÀS INVESTIGAÇÕES INTERNAS DOS PROGRAMAS DE COMPLIANCE
}

\author{
THE PROTECTION OF TRANSINDIVIDUAL LEGAL \\ RIGHTS AND LIMITS TO INTERNAL INVESTIGATIONS IN \\ COMPLIANCE PROGRAMS
}

\author{
JOSÉ RAFAEL FONSECA DE MELO \\ Universidade do Estado do Rio de Janeiro (UERJ) \\ rafaelfonsecademelo@hotmail.com
}

GUILHERME DUTRA MARINHO CABRAL

Universidade Vale do Rio Doce guilherme.cabral@univale.br

\begin{abstract}
Resumo
Os programas de compliance surgiram no contexto da denominada sociedade de riscos, como instrumento de controle das atividades econômicas potencialmente lesivas à sociedade e à própria pessoa jurídica. Dentre as medidas capazes de impedir ou atenuar a responsabilidade penal da empresa, destaca-se a investigação corporativa que auxilia o poder público a apurar a responsabilidade individual do funcionário no crime. Diante da possibilidade desse procedimento violar garantias processuais penais básicas do suspeito, a pesquisa tem como objetivo analisar possíveis limites às investigações internas dos programas de integridade, como forma de evitar a aplicação de sanções abusivas aos empregados. Ao final concluiu-se que o programa de compliance poderá prevenir a intervenção indevida da empresa nas liberdades do trabalhador elaborando um Código de Investigação Interna, fixando um Estatuto dos Trabalhadores ou simplesmente adotando as diretrizes previstas no Decreto 8.420/15, para os casos de processo administrativo de responsabilidade.
\end{abstract}

Palavras-chave: Sociedade de risco. Compliance. Investigação interna. Limites.

Compliance programs emerged in the context of the so-called risk society, as an instrument to control economic activities potentially harmful to society and to the legal 
entity itself. Among the measures capable of preventing or mitigating the criminal liability of the company, stands out the corporate investigation that helps governments to investigate the employee accoutability for the crime. Given the possibility of this investigation violating basic criminal procedural guarantees of the suspect, the article aims to analyze possible limits to internal investigations in integrity programs, as a way to avoid the application of abusive sanctions to employees. In the end, it concludes that compliance internal programs may prevent companies to harm the freedom of workers by elaborating an Internal Code of Investigation, establishing a Workers' Statute or simply adopting the guidelines provided for in Brazilian Decree $8.420 / 15$ for cases of administrative liability proceedings.

Keywords: Risk society. Compliance. Internal investigation. Employees. Freedom.

\begin{abstract}
Sumário: Introdução. 1 Sociedade de riscos e direito penal econômico. 2 Gestão de riscos em programas de compliance. 2.1 Departamentos de compliance e prevenção criminal. 2.1.1 Limites processuais às investigações internas dos programas de compliance. Conclusão. Referências bibliográficas.
\end{abstract}

\title{
Introdução
}

Desde a segunda metade do século XX, a revolução tecnológica promovida pela inserção da eletrônica, da informática e da automação nos processos de produção tem modificado não somente as condições de vida na sociedade pós-moderna, como também a forma do ser humano lidar com os riscos inerentes a essas atividades. A ausência de conhecimento científico para delimitar, com segurança, as consequências a médio e longo prazo de atividades perigosas fomentou o surgimento da denominada sociedade de riscos, caracterizada por um modo de reprodução de vida material constantemente exposto a riscos, independentemente do local e do estrato social ocupado pelo cidadão. Em razão da sua utilidade social, tais atividades passaram a ser fomentadas ou toleradas pelo Estado, a exemplo do que ocorre com a exploração da mineração, com as pesquisas nucleares e genéticas, com o transporte aéreo e com a indústria farmacêutica.

Para reduzir os riscos sociais inerentes a essas e outras atividades, o Estado passou a regulamentar intensamente a intervenção pública e privada na economia, inclusive por meio do Direito Penal. A tentativa de proteger bens jurídicos transindividuais mediante a ameaça de pena a pessoas físicas e jurídicas, então originou novos ramos nas ciências criminais, como é o 
caso do Direito Penal Econômico.

Como reação à possibilidade de responsabilização penal da pessoa jurídica, empresas de médio e grande porte precisaram adotar mecanismos de autorregulação da própria atividade econômica, e impulsionaram o desenvolvimento dos denominados programas de integridade empresarial. Também conhecidos como programas de compliance, os dispositivos de gestão de riscos, não raras vezes, contam com procedimentos internos de investigação de infrações trabalhistas, civis, ambientais e criminais cometidas contra ou a favor da empresa. Como consequência lógica da suspeita de comportamentos irregulares, o departamento de integridade instaura procedimentos internos de investigação e, em caso de confirmação, são aplicadas sanções ao infrator levando-se em consideração a natureza jurídica do desvio e as consequências do ato.

Nesse sentido, o objetivo da pesquisa consiste em analisar os limites das investigações internas nos programas de integridade empresarial, especificamente quanto à possível violação de direitos do trabalhador durante a apuração de condutas irregulares classificadas como crime. A relevância jurídica da pesquisa reside no fato de que a investigação corporativa de ilícitos penais pode impor consequências negativas ao empregado tanto durante, como após o procedimento interno. Havendo apuração abusiva de tais comportamentos, além de o suspeito ficar exposto, no curso da investigação, a inúmeros transtornos psíquicos indevidos - como aplicação de estigmas, a transferência de cargo e a exclusão das relações sociais dos demais colegas -, as sanções aplicadas ao desviante poderão ensejar a rescisão do seu contrato do trabalho, a instauração de ação civil de reparação de dano, bem como o oferecimento de notícia de crime, sem que algumas garantias processuais penais básicas do funcionário tenham sido preservadas. O método de investigação adotado consiste na pesquisa bibliográfica, compreendida pelo estudo de livros, artigos científicos e legislações relacionadas ao tema.

Após esta Introdução, o artigo irá contextualizar a função desempenhada pelo Direito Penal Econômico no marco da sociedade de riscos, e discorrerá sucintamente sobre alguns mecanismos de autorregulação das empresas. Na terceira seção serão abordados os objetivos, as espécies, o percurso histórico, além de algumas teorias e pilares dos programas de compliance, enquanto a subseção irá analisar mecanismos capazes de impor limites às investigações internas e, assim, prevenir a violação de direitos de testemunhas e de suspeitos envolvidos na apuração do crime. Por fim, o artigo apresenta as conclusões obtidas com a pesquisa a guisa dos objetivos que lhe foram propostos.

\section{SOCIEDADE DE RISCOS E DIREITO PENAL ECONÔMICO}


A partir da década de 1980, consolidou-se nas ciências sociais a ideia de que o desenvolvimento de novas tecnologias na produção e distribuição de bens e serviços provocou inegáveis progressos, sem um conhecimento científico seguro acerca das consequências diretas e indiretas dessas atividades.

O marco para o surgimento da denominada sociedade de riscos teria sido o acidente nuclear de Chernobyl, responsável por provocar diretamente a morte de trinta e uma pessoas por radioatividade no ano de 1986 e por disseminar o perigo de câncer a outras quatro mil, em longo prazo. Outra tragédia que contribuiu para questionar os efeitos nefastos do uso inadequado das novas tecnologias ocorreu em 1984, na Índia, com a morte e a contaminação de milhares de pessoas após a emissão de produtos químicos na fábrica Union Carbide.

Em decorrência desses fatos, sociedades industrializadas do Ocidente passaram a se preocupar com os riscos globais das novas tecnologias empregadas nas atividades econômicas, objetivando controlar riscos relativamente desconhecidos à convivência humana.

Assim, no ano de 1986 o sociólogo alemão Ulrich Beck publica o livro risco social em direção a outra modernidade, argumentando que as sociedades altamente industrializadas enfrentam riscos ambientais e tecnológicos que não são meros efeitos colaterais do progresso, mas centrais e constitutivos destas sociedades, ameaçando toda forma de vida no planeta (GUIVANT, 1998).

Destarte, a sociedade de risco pode ser interpretada como resultado do desenvolvimento de um modelo econômico que surge na Revolução Industrial, baseado na produção e distribuição de bens em larga escala. Diante da necessidade de obter o maior número possível de consumidores com o menor custo de produção, as inovações tecnológicas - financiadas tanto pelo governo como pelo capital - aceleram o progresso social sem, contudo, o correspondente avanço científico no controle dessas atividades.

Adificuldade de estabelecer limites espaciais ou temporais aos novos riscos democratizou também o potencial danoso dessas atividades, incluindo dentre as possíveis vítimas os próprios agentes sociais que se beneficiam da produção e da distribuição de bens e serviços perigosos. Também denominado como efeito bumerangue, esse sentimento geral de insegurança é incrementado pelos meios de comunicação de massa e resultam, ao final, na demanda social por novos mecanismos de controle.

A ideia de um risco inerente às relações sociais, nesse sentido, impõe o desenvolvimento de instrumentos formais de controle que preservem a funcionalidade das atividades perigosas, ao mesmo tempo em que o poder púbico fomenta ou tolera a sua exploração dentro de limites previamente fixados, como são os casos das atividades de mineração, petróleo e construção civil, as indústrias de siderurgia, metalurgia e farmacêutica, as tecnologias atômicas, genéticas 
e de informática, e os serviços de transportes terrestre, naval e aéreo.

A posição de garantia dos fornecedores desses bens e serviços contra eventuais danos à sociedade, por sua vez, lhes impõe a adoção de medidas para evitar ofensas tanto à segurança dos trabalhadores como ao meio ambiente, à integridade física ou patrimonial de terceiros ou dos próprios clientes.

O desenvolvimento tecnológico também pode provocar prejuízos na ordem econômica, não somente por meio de desastres ambientais e sociais, como também pela prática de crimes que assegurem vantagens ou monopólios no mercado. Isso porque,

\begin{abstract}
A absoluta liberdade econômica conduz à escravidão dos pequenos a um número reduzidos de magnatas. Ao Estado cúmpre [sic.] cuidar do bem estar da coletividade, fomentando e defendendo a pequena economia contra os "trusts", "cartéis" e "anéis" de produção, tão comuns na época do grande capitalismo, que terminam colocando o povo na sua inteira dependência econômica e por fim submetendo o próprio Estado e pondo-o a serviço dos seus interesses particulares. (FRANCISCO CAMPOS, apud LYRA, 1940, p. 84).
\end{abstract}

Além dos riscos decorrentes de trusts e cartéis, a ordem econômica pode ser abalada por fraudes fiscais, pela manipulação de taxas no mercado de ações, pela criminalidade informática e tantos outros fenômenos conhecidos como crimes de colarinho branco.

Em razão da natureza desses delitos, o reconhecimento do risco como elemento central da organização social orienta uma política criminal comprometida com a criminalização de condutas de perigo abstrato, a proteção da ordem econômica ${ }^{1}$, a elaboração de normas de cuidado, a conversão do erro de tipo em erro de proibição ${ }^{2}$, além de reformulações dogmáticas para omissão ${ }^{3}$ e autoria ${ }^{4}$ delitivas.

A dificuldade de o Estado regulamentar atividades econômicas complexas também impõe a transferência, para as próprias empresas, da identificação e da gestão dos riscos da sua atuação no mercado, obrigando-as a conformar suas práticas empresariais a padrões técnicos previamente estabelecidos pelo poder público.

Segundo Coca Vila (p. 46-47ᄀ),

[...] la autorregulación no supondría uma retirada del Estado, ni la admisión de la incapacidad de regular el mundo empresarial, sino, simplemente um cambio de rumbo em la estratégia reguladora. Si el Estado es incapaz de regular desde fuera las empresas, la única

\footnotetext{
1 Definida como "regulação jurídica da participação estatal na economia”, por Bajo Fernández (DPE, pp. 37 ss.), ou como “atividade interventora e reguladora do Estado na economia”, por Tiedmann (Wirtschaftsstrafrecht 1, p. 50) (MARTIN, 2005, p. 54).

2 "También se há indicado que los tipos del Derecho penal económico-empresarial se estructuram muy frecuentemente como tipos fuertemente normativizados, en particular como leyes en blanco o tipos con elementos de valoración global del hecho. Así las cosas, si fueran calificados como errores de tipo, la mayor parte de los erros vencibles em materia penal económica darían lugar a impunidad de la conducta. En la Jurisprudência y em certa doctrina el processo há sido, entones, el inverso: la del error de prohibición, a fin de sancionar - de forma atenuada - los errores vencibles de los sujetos" (SILVA SANCHÉZ, 2013a, p. 52).

3 Como a teoria da cegueira deliberada.

4 A exemplo da imputação de ações neutras e da culpa organizativa.
} 
solución posible sería valerse de ellas para conseguir sus objetivos. Por paradójico que pueda parecer, la autorregulación no responderia a um impulso desregulador, sino muy ao contrario, supondría uma mejoría cualitativa y cuantitativa em la intervención estatal, em la medida em que el Estado podría logar uma regulación más rigurosa, específica y eficaz.

Nesse sentido, a autorregulação da atividade empresarial se manifesta tanto de forma voluntária, como fomentada ou regulada pelo Estado. Na primeira hipótese, a sociedade empresarial define, sem nenhuma intervenção estatal, normas internas de atuação como Código de Ética, Código de Conduta, princípios, diretrizes e protocolos de atuação destinados ao controle de riscos permitidos e à otimização da produção ou da distribuição de bens e serviços.

$\mathrm{Na}$ autorregulação fomentada, por sua vez, o Estado estabelece princípios gerais de atuação, e incentiva a pessoa jurídica a fixar normas internas para sua estrutura organizacional, enquanto na autorregulação regulada o Estado obriga as empresas a elaborarem normas internas de controle da sua atividade, mediante a ameaça de sanções administrativas ou criminais.

No Brasil, a autorregulação regulada da atividade empresarial pode ser encontrada na Lei 9.613/98, que define procedimentos de combate à lavagem de dinheiro. Uma das hipóteses de autorregulação regulada se dá obrigando pessoas físicas e jurídicas que atuam na captação, intermediação e aplicação de recursos financeiros de terceiros a a) identificar clientes e manter seus cadastros atualizados, b) preservar o registro sobre toda transação em moeda nacional e estrangeira que ultrapassar limite fixado pela autoridade competente, c) implementar políticas, procedimentos e controles internos compatíveis com seu suporte e volume de operações. Em caso de descumprimento desses deveres, os agentes econômicos serão punidos com advertência, multa, inabilitação da atividade por até dez anos, ou a cassação ou suspensão do seu funcionamento.

Independentemente do modelo adotado para assegurar a autorregulação, as sociedades empresariais poderão desenvolver mecanismos complexos de controle de riscos e de conformação da atividade às legislações cível, administrativa, tributária e penal. Amplamente conhecidos como programas de Compliance, os procedimentos internos de integridade empresarial tem como principal objetivo atenuar ou excluir a responsabilidade penal das pessoas jurídicas pela prática de delitos econômicos ${ }^{5}$.

\section{GESTÃO DE RISCOS EM PROGRAMAS DE COMPLIANCE}

\footnotetext{
5 Lei 12.846/13 (Lei anticorrupção), art. $7^{\circ}$. Serão levados em consideração na aplicação das sanções: [...] VIII - a existência de mecanismos e procedimentos internos de integridade, auditoria e incentivo à denúncia de irregularidades e de aplicação efetiva de códigos de ética e de conduta no âmbito da pessoa jurídica.
} 
No marco de uma sociedade de riscos, a dinâmica globalizada do processo de produção e distribuição de bens e serviços demanda uma complexa regulamentação das relações econômicas. Apesar da diversidade de normas administrativas, tributárias, civis, trabalhistas e penais que disciplinam a intervenção da iniciativa privada no mercado, não são raros os casos em que a atividade empresarial se reveste de irregularidades com potencial lesivo para o meio ambiente, para as relações de consumo ou para administração pública.

Por outro lado, o nível de conformação da pessoa jurídica à legislação pode ser influenciado por inúmeros fatores, como o desconhecimento da norma a ser cumprida, a prevalência dos interesses econômicos sobre as obrigações legais, a ausência de pessoal especializado para determinadas funções, a dificuldade de comunicação entre os setores que compõe a estrutura organizacional e o próprio modelo de gestão implantado na sociedade comercial.

Com a transferência, para a iniciativa privada, da responsabilidade pela identificação e gestão dos riscos permitidos da sua atividade, tem se consolidado na economia a consciência acerca da necessidade premente de a empresa estabelecer mecanismos internos de gestão de riscos e adequar sua atuação às normas legais. Esses programas de integridade empresarial não só permitem prevenir a responsabilidade penal da pessoa jurídica, como também evitam que sanções administrativas ou cíveis inviabilizem a permanência da sociedade empresarial no mercado.

Em relação às sanções penais, os programas de compliance têm como preocupação primordial coibir a prática de crimes contra ou a favor da empresa, a exemplo do ocorre nos casos de corrupção ativa, branqueamento de capitais, formação de cartéis, concorrência desleal, contravenções ambientais e delitos contra a segurança do trabalhador ou as relações de consumo.

Nesse sentido, o artigo 41 do Decreto 8.420/15 afirma que

[...] programa de integridade consiste, no âmbito de uma pessoa jurídica, no conjunto de mecanismos e procedimentos internos de integridade, auditoria e incentivo à denúncia de irregularidades e na aplicação efetiva de códigos de ética e de conduta, políticas e diretrizes com objetivo de detectar e sanar desvios, fraudes, irregularidades e atos ilícitos praticados contra a administração pública, nacional ou estrangeira.

Em razão das especificidades de cada empresa, o programa de compliance deve variar conforme o porte e a natureza das atividades desenvolvidas, com o objetivo de otimizar a gestão dos riscos permitidos das suas operações. Durante a elaboração do programa podem ser observados fatores como a quantidade de funcionários, a complexidade hierárquica interna, o setor do mercado em que atua, o grau de interação com o poder público e com agentes privados intermediários - como consultores ou representantes comerciais -, a quantidade e a localização das pessoas jurídicas que integram o grupo econômico, a classificação como microempresa ou 
empresa de pequeno porte, etc.

A importância do programa de integridade reside no fato, por exemplo, de a empresa ser punida com menos rigor na hipótese de responsabilidade administrativa da pessoa jurídica. Assim, a sanção será atenuada levando-se em consideração o nível de comprometimento da alta direção com o programa de integridade, a fixação de padrões de conduta e código de ética a todos os funcionários, a periodicidade dos treinamentos e das análises de risco, a idoneidade contábil das transações registradas, a qualidade do sistema informático que alimenta o banco de dados, a existência de procedimentos específicos para prevenir ilícitos em licitações e na execução de contratos administrativos, a eficiência dos canais de denúncia, a estrutura e independência do departamento de compliance, as medidas disciplinares impostas nos casos de violação do programa, etc.

Por se tratar de fenômeno relativamente recente nas ciências criminais, Lothar Kuhlen (2013) sugere a formulação de uma teoria sobre compliance e Direito Penal por meio de representações adequadas da sua significação social. Para tanto, destaca que uma das características penalmente relevantes do instituto compreende a incorporação de novos valores e virtudes aos programas de integridade.

Em que pese a possibilidade desses elementos se afigurarem conflitantes com alguns interesses econômicos concretos da empresa, a assunção de novos valores para sua atuação no mercado pode ser identificada pela ideia de Responsabilidade Social Corporativa (RSC) da pessoa jurídica. Segundo Nieto Martín (2015), a RSC tem como pressuposto o fato de que a intervenção das empresas na economia também implica responsabilidades sociais e políticas para com a comunidade. Demais disso, a RSC seria necessária para um crescimento econômico continuado e para atrair investidores no futuro, já que a proteção das relações com os consumidores e com as comunidades locais normalmente favorece a produção e garante a estabilidade da empresa na economia. Assim,

\footnotetext{
Dentro de sus contenidos más antigos se encontrarían também la preocupación por el medio ambiente y el diálogo social. [...] Na Europa, las primeras manifestaciones de la RSC consistieron en lo compromiso de la empresas com el diálogo social y una perspectiva interna, de gestión de recursos humanos, que abarcaria la promoción de la seguridade en le trabajo, el aprendizaje permanente, la conciliación de la vida laboral, las políticas de igualdad, etc. Finalmente, la RSC, em la última de sus versiones, incorpora el compromisso com valores sociales, como o respecto a los derechos humanos, la lucha contra la corrupción o la preocupación porque em la actividad de la empresa se respete la legalidade. (NIETO MARÍN, 2015, p. 41).
}

O segundo elemento penalmente relevante para construção da teoria corresponde à consolidação de um Direito Penal de risco. O núcleo duro dos programas de integridade 
empresarial parece ser justamente a tentativa de reduzir riscos proibidos durante o seu funcionamento para evitar, sobretudo, a responsabilidade penal da pessoa jurídica. Isso porque, “así como la percepción del aumento de los riesgos jurídico-penales por parte de las empresas es el motor, la minimización de estos riesgos es el fin de los esfurezos actuales sobre compliance" (KUHLEN, 2013, p. 65, destaques no original).

Demais disso, como corolário lógico da globalização das relações econômicas e dos riscos de danos que lhe são inerentes, a possibilidade de responsabilização penal de empresas multinacionais seria a terceira característica a ser considerada em uma teoria sobre compliance e Direito Penal.

O último eixo reside na função de autorregulação atribuída aos programas de conformidade legal. Para evitar responsabilidades administrativas e penais da pessoa jurídica, os mecanismos internos de controle de riscos compreendem, dentre outras coisas, o treinamento contínuo dos funcionários acerca das funções desempenhadas, a fixação de padrões de conduta e de código de ética, a existência de auditorias e de canais de denúncia para comunicação de fatos impróprios, assim como a investigação e a punição de comportamentos irregulares.

Estudiosos do tema sustentam ainda que os programas de compliance devem ser elaborados a partir de alguns pilares. O primeiro seria a cultura de integridade empresarial, compreendido pela ideia de que todos os funcionários, incluindo os diretores, precisam internalizar a importância de conformar seus atos ao ordenamento jurídico. A vontade geral de atuar corretamente seria fomentada tanto por meio de assessorias especializadas aos funcionários, como disponibilizando canais de denúncias de irregularidades, divulgando informativos com os Códigos de Ética e de Conduta, e esclarecendo as competências funcionais e eventuais responsabilidades administrativas e penais de cada.

Não obstante a isso, argumenta-se também que o respeito à cultura de integridade contribui para redução de fatores criminógenos no trabalho, já que

Las infraciones a las normas son favorecidas especialmente por um clima de erosión normativa, por técnicas de neutralización al interior de la empresa para facilitar las violaciones normativas, por pressiones a los trabalhadores para que encontren "soluciones inovadoras” así como por oportunidades para la comisín de delitos (SIEBER, 2013, p. 96).

O segundo pilar consiste em fixar claramente o objetivo geral do programa, e delimitar os objetivos específicos de cada setor. Dessa forma, os riscos eventualmente criados durante o funcionamento da empresa podem ser facilmente imputados ao setor responsável pelo controle da respectiva atividade.

O terceiro pilar está relacionado à identificação e à gestão permanente dos riscos de danos 
nas operações empresariais. Destarte, ao formular o programa de integridade, a organização deve inventariar quais são as implicações de determinadas infrações legais para a coletividade, adotando em seguida medidas concretas de contenção de riscos, como a seleção adequada das pessoas que irão gerenciar os riscos e a capacitação permanente dos membros da empresa.

$\mathrm{O}$ quarto pilar de um programa corresponde à regulamentação das competências de cada setor, conjuntamente com a atribuição de responsabilidades aos funcionários que exercem dever de vigilância. Segundo Coca Vila (2013, p. 58),

\footnotetext{
la delimitación de las esferas competenciales permite saber com claridad quién es el responsable por cada processo en la empresa, dificulta la temida disolución de la responsabilidad en el seno de grandes corporaciones y facilita la imputación de responsabilidade tras la infracción.
}

Outro pilar seria o desenvolvimento de um sistema interno de comunicação que permita controlar riscos por meio da gestão de dados. A empresa deve ofertar aos funcionários o conhecimento atual, claro e detalhado dos riscos de danos provocados por sua atividade, disponibilizando canais fluidos e diretos de informação para esclarecimento de dúvidas e sugestões de redução de riscos. O programa de integridade também pode impor deveres de transmissão e de consulta dessas informações aos funcionários, com o intuito de promover o funcionamento integrado e harmônico de seus setores.

Em regra, incumbe ao oficial de compliance a função de informar a cúpula da empresa as situações de risco registradas no sistema (bottom-up) para que o órgão diretivo, em seguida, transmita essa informação aos funcionários envolvidos na atividade perigosa (top-down).

O último pilar diz respeito ao sistema de supervisão e de aplicação de sanção disciplinar no interior da empresa. Considerando o fato de que oficial de compliance é a pessoa responsável por desenvolver, aplicar e supervisionar o programa de integridade, constitui responsabilidade sua organizar o registro físico e virtual de toda cadeia produtiva e colacionar decisões que foram adotadas no passado para solucionar casos emblemáticos (jurisprudência corporativa). O processo de supervisão também compreende o monitoramento da atuação de informantes (whistleblower), e a gestão de canais de denúncias oferecidos aos trabalhadores. Ao final, o oficial de compliance poderá propor o aperfeiçoamento dos mecanismos de controle de riscos, bem como aplicar medidas disciplinares aos funcionários desviantes e comunicar tal fato às autoridades públicas.

\subsection{DEPARTAMENTOS DE COMPLIANCE E PREVENÇÃO CRIMINAL}


Conforme mencionado, os programas de compliance têm como principais objetivos impedir a responsabilidade penal da pessoa jurídica, e dificultar a punição individual de seus dirigentes. Em regra, a função de prevenção de riscos criminais é delegada ao departamento de compliance, cuja coordenação fica a cargo do compliance officer, ou simplesmente oficial de cumprimento.

Na prática, a atuação do departamento de compliance na elaboração, execução e aprimoramento do programa será decisiva para prevenir delitos praticados tanto a favor como contra a empresa, e para permitir a delimitação da responsabilidade individual dos funcionários com fundamento nas competências e nos deveres de vigilância que lhes foram atribuídos.

Nesse sentido, uma das vantagens do programa de integridade diz respeito à sua capacidade de redistribuir a responsabilidade por ilícitos entre os dirigentes, o oficial de cumprimento e demais empregados, de modo que

\begin{abstract}
o empregado, como executor direto, pode responder como autor ante o domínio da ação; o oficial de compliance pode, por sua vez, responder como autor diante do descumprimento de suas funções de supervisão e vigilância; por fim, o dirigente pode responder, igualmente, como autor, caso tenha procedido a uma "delegação defeituosa" das funções ao setor responsável. (SOUZA, 2015, p. 140).
\end{abstract}

Na qualidade de pessoa responsável pela fiscalização do programa de integridade, o profissional de cumprimento assume parcialmente a posição de garantia originariamente ocupada pelos administradores da empresa. Essa delegação de competência representa um mecanismo concomitante de transferência e transformação da posição anterior de garantia: transferência porque, com a delegação, o delegante faz surgir uma posição de garantia no delegado; e transformação porquanto a posição de garantia do delegante não desaparece, mas se modifica. Assim,

\begin{abstract}
Al delegante ya no le compete el deber de control directo de los fócos de riesgo que se hallan em el ámbito de competência del delegado. Pero sí le incumben una serie de deberes com objeto diverso: la correta slección, formación - si fuera precisa - e información del delegado; a dotación a este com los médios necessários para el cumplimiento de sus funciones; la coordinación de la actuación de los diveros delegados; y sobre todo - al enos, eso es lo que suele indicarse - el dever de vigilância. (SÁNCHEZ, 2013, p. 80)
\end{abstract}

Por meio da delegação do dever de vigilância, a atuação do compliance officer compreende, sobretudo, a obtenção de conhecimento e a transmissão dessas informações ao superior hierárquico ou à pessoa competente para correção da situação defeituosa. Na hipótese de omissão desses profissionais quanto à adoção das medidas sugeridas, o oficial de cumprimento poderá se resguardar de eventual responsabilidade criminal comunicando o fato ao ombudsman 
interno ou a um advogados sem vínculo institucional.

Os oficiais de cumprimento não são incumbidos de dispor de medidas de prevenção de acidentes de trabalho, de evitar danos ao meio ambiente, de controlar a qualidade de alimentos ou a segurança dos produtos químicos armazenados, já que a gestão desses riscos é determinada, pelo próprio programa de integridade, a pessoas específicas da empresa. Segundo Prittzwitz (2013, p. 216, destaques no original), “[...] el deber como la capacidade de actuar del compliance officer están orientados a informar sobre el delito, pero no a tomar medidas en contra de este o a evitarlo (aunque ell sea fisicamente posible).

As competências atribuídas aos profissionais de cumprimento correspondem à regulamentação de normas de funcionamento da pessoa jurídica, à coordenação e supervisão dos atos realizados pelas pessoas responsáveis pela segurança da atividade empresarial, sistematização do procedimento interno de investigação de infrações e de aplicação de sanção disciplinar, etc.

Destarte, o oficial de cumprimento responderá como coautor de crimes praticados por terceiros quando não tiver impedido o resultado típico, “[...] si tenta al respecto uma posición de garantia y si su actitude subjetiva se corresponde con la exigida por el corrispondiente delito: si omitió dolosamente si el delito es de exclusiva comisión dolosa; si su omisión fue descuidada em le supuesto de que se sancione la comisión imprudente" (SÁNCHEZ, 2014, p. 326, destaques no original).

Se, por outro lado, o compliance officer não for garante - porque a empresa não ocupa a posição de garantia em relação ao delito, ou porque o profissional não foi delegado para essa função -, responderá como partícipe do crime praticado pela pessoa jurídica quando a violação dos seus deveres de garantia tiver facilitado a comissão dos referidos crimes. Em regra, a responsabilidade penal do oficial de cumprimento, como partícipe de delitos alheios, ocorrerá por omissão sua no dever de investigar o crime denunciado.

Por sua vez, o departamento de integridade pode apresentar inúmeras atribuições, como elaborar informativos e organizar cursos de capacitação dos funcionários, disponibilizar canais de denúncia anônima, e promover a investigação de infrações penais.

A importância de informes periódicos corporativos na prevenção de delitos reside no fato de que os mesmos reforçam os objetivos e os valores do programa ${ }^{6}$, ressaltam a importância do Código de Ética e do Código de Conduta, esclarecem as responsabilidades de cada setor produtivo na gestão dos riscos empresariais, sugerem padrões de conduta e, por fim, descrevem as consequências civis, trabalhistas e penais de comportamentos impróprios.

\footnotetext{
6 Segundo Ulrich Sieber (2013), os objetivos do programa estão relacionados com a tentativa de impedir fatos delitivos como corrupção, lavagem de dinheiro, financiamento de terrorismo, delitos contra a livre concorrência - principalmente o de formação de cartel -, crimes contábeis, defraudações tributárias, abuso de informação privilegiada, delitos ambientais e revelação de segredos comerciais. Os valores do programa, por sua vez, referem-se aos valores econômicos e à transparência da empresa.
} 
O departamento de compliance também pode organizar cursos regulares de capacitação de empregados para aprimorar as competências dos funcionários, e evitar riscos proibidos no curso da atividade empresarial.

\subsubsection{Limites processuais às investigações internas dos programas de Compliance}

Em razão da dificuldade do departamento de compliance conhecer todas as situações irregulares que acontecem no interior da empresa, as investigações internas destinadas a apurar comportamentos desconformes de empregados, diretores ou conselheiros normalmente são impulsionadas pela delação dos próprios colegas, mediante canais de denúncia e pelo oferecimento de incentivo à comunicação, como a estabilidade no emprego, a garantia de anonimato, o pagamento de recompensa em dinheiro, bem como a atenuação ou o próprio perdão da sanção que deveria ser aplicada ao declarante.

A existência de sistemas de denúncia (whistleblowing) integrados ao programa de integridade empresarial também representa um importante fator de atenuação da responsabilidade penal da pessoa jurídica, seja pela confissão do crime, seja pela possibilidade de reparar o dano causado e aprimorar o programa de integridade.

Em que pesem essas vantagens, críticos do sistema de denunciação argumentam que os trabalhadores, nesses casos, passam a desempenhar a função de polícia a serviço do empresário, impossibilitando uma boa convivência no grupo (RAGUÊS E VALLES, 2014). Como consequências negativas, a política de delação desencadearia um clima de grave desconfiança entre empregados e diretores, e prejudica as próprias pessoas que integram a companhia. A delação também pode ser utilizada com a finalidade de prejudicar ou vingar funcionários com os quais o declarante não possui boa relação, ou para desequilibrar a disputa por cargos ou posições de prestígio na empresa. Por fim, argumenta-se que o empregado denunciado sofreria intensa estigmatização e exclusão no âmbito das suas relações profissionais, mesmo antes de saber da incriminação.

Independentemente disso, a investigação também poderá ser impulsionada por auditorias internas que identificam condutas aparentemente ilícitas, por parte de algum funcionário. No marco de uma economia complexa e fluída, com intensa regulação dos atos administrativos da pessoa jurídica, a auditoria interna representa outro importante instrumento de gestão dos riscos da sua atividade. Assim, a auditoria contábil, objetivando aperfeiçoar o nível de funcionamento do sistema, auxilia os programas de integridade a detectar comportamentos fraudulentos ou corruptos no âmbito da companhia.

Após conclusão da auditoria ou do oferecimento da denúncia, instaura-se então 
investigação interna para apurar a suposta infração, designando-se, para tanto, uma equipe de trabalho especializada no assunto.

As investigações empresariais internas são realizadas de distintas formas. Levandose em consideração o objeto da apuração, a investigação pode recair sobre ilícitos penais, ilícitos extrapenais - como irregularidades trabalhistas ou infrações às normas de proteção de dados -, e inadimplementos contratuais. As investigações também podem se destinar a apurar desvios consumados, o a prevenir a prática de outros. A posição ocupada pelo suspeito define a apuração de infrações cometidas a) pelos próprios empregados contra a empresa, como furto de bens, desvio de dinheiro ou apropriação indébita, b) por um funcionário em desfavor de outro, a exemplo dos crimes contra a honra, do estupro ou do assédio sexual no interior da organização; c) por funcionários da empresa, em nome da mesma, por meio do fenômeno conhecido como delito empresarial; d) pelo empresário, nas hipóteses de violação do dever de garantia sobre a vida, a integridade física e a saúde dos trabalhadores.

Por se tratar de um procedimento interno reativo da empresa contra a suspeita de irregularidades, a investigação interna eventualmente restringe direitos fundamentais dos trabalhadores - como a intimidade e a liberdade -, e provoca consequências negativas ao infrator mediante aplicação de sanções disciplinares, demissões, instauração de ação civil ou oferecimento de notícias de crime às autoridades públicas. Dadas essas particularidades, o instituto deve ser considerado um procedimento jurídico igualmente sujeito a normas de atuação e com delimitação clara do seu objeto.

Nesse sentido, Nieto Martín (2015a, p. 235) sugere a elaboração de um Código de Investigação Interna no âmbito dos programas de integridade, já que "la existencia de normas internas preestabelecidas, conocidas por todos los empleados y aprobadas por la dirección de la empresa, legitima la realización de las investigaciones y evita el que se cometan errores, al regular previamente los problemas que pueden aparecer".

A investigação corporativa disciplinada pelo programa de compliance também pode ser fracionada em quatro fases, em respeito aos demais procedimentos destinados a apurar fatos e impor sanções, quais sejam: preliminar, abertura de investigação, realização de investigação e comunicação dos resultados com aplicação de sanção.

Na primeira, exige-se o mínimo de verossimilhança da imputação para evitar restrições desarrazoadas de direitos do trabalhador. Aqui, a suspeita justificada da prática de infração será suficiente para instauração do procedimento, quando o fato imputado não constituir crime. Tratando de ilícito penal, torna-se necessário que a acusação esteja lastreada em forte suspeita, como ocorre na persecução criminal. Em ambos os casos, tal requisito poderá evitar a adoção de medidas invasivas à intimidade e liberdade do empregado, fundamentadas em incriminações 
de má fé, pelo anonimato de alguns canais de denúncias.

Verificada a plausibilidade da imputação, o departamento de integridade tem o dever de instaurar o procedimento interno de investigação, por força dos princípios da boa governança corporativa e da responsabilidade social. Como corolário lógico do dever de diligência dos administradores para com a legalidade dos atos empresariais, a omissão do grupo na apuração interna de crimes pode acarretar tanto a responsabilidade penal da pessoa jurídica, como a responsabilidade social dos seus gestores.

Ato contínuo, o departamento de Compliance designará o profissional responsável pela investigação, e comunicará o Conselho de Administração quando a infração representar grave violação ao programa de integridade.

Tratando-se de conduta definida como crime, torna-se de bom alvitre que a investigação seja presidida por um advogado criminal da empresa, e que os documentos produzidos no curso do procedimento sejam devidamente acautelados. Nos demais casos, a apuração será mais eficiente se for coordenada por pessoas com formação especializada no assunto, como o departamento de direitos humanos quando se tratar de estupro, os auditores internos diante da suspeita de fraude, e os setores de controle de qualidade nas hipóteses em que a atividade aparentemente defeituosa ameaçar a integridade física do consumidor, o meio ambiente ou a proteção dos trabalhadores.

$\mathrm{O}$ ato de nomeação do responsável deve conter o objeto da investigação, o prazo estimado para sua duração, e a finalidade consignada para a mesma, isto é, se a intervenção pretende apenas corrigir situações defeituosas ou se também tem como objetivo aplicar sanções e auxiliar procedimentos penais ou administrativos. Na sequência, o departamento de compliance analisa o plano de trabalho apresentado pelo presidente do procedimento, com cronograma da atividade, a relação de testemunhas e as provas documentais e periciais que pretende produzir.

Aprovado o plano de trabalho, são nomeados os demais integrantes da equipe de investigação levando-se em consideração a competência funcional para apurar a infração, e o compromisso dos mesmos em não tornar públicos os resultados da apuração.

Na terceira fase, são executados os atos de investigação com estrita observância ao plano de trabalho aprovado pelo departamento de compliance. Os riscos decorrentes do procedimento adotado são diversos porque, pretendendo atenuar ou evitar a responsabilidade penal da pessoa jurídica, a equipe de trabalho pode incorrer em crimes ou contravenções ao violar indevidamente a intimidade e o sigilo das comunicações dos funcionários, ou coagir o funcionário a prestar depoimento sob a ameaça de demissão (NIETO MARTÍN, 2015a, p. 235).

Demais disso, considerando o fato de que um dos meios de investigação mais comuns consiste na análise de ferramentas e tecnologias da informação (computador de trabalho, caixa 
postal eletrônica, acesso à internet, telefones fixos e móveis, etc.), é possível que a equipe de trabalho adote medidas invasivas à intimidade do trabalhador, em afronta ao princípio da proporcionalidade.

Nesse sentido, uma das maiores controvérsias no âmbito das investigações corporativas refere-se à possibilidade de conversão desses instrumentos de controle de riscos em sistema de justiça de empresa, ou de privatização do processo penal.

No primeiro caso, os crimes perpetrados em desfavor das pessoas jurídicas são apurados e solucionados internamente com a demissão do funcionário e a assinatura de termo de ressarcimento dos prejuízos que lhe foram causados, sem qualquer intervenção do Direito Penal. No segundo, a investigação corporativa passa a ser considerada a antessala da persecução criminal porque autoriza a atenuação ou a obstrução da responsabilidade penal da pessoa jurídica, quando o procedimento interno produzir provas que auxiliem o poder judiciário na individualização das condutas desviantes.

Para assegurar um equilíbrio entre o dever da empresa de investigar e o direito dos empregados contra imputações abusivas, é imprescindível delimitar, no próprio programa de integridade, garantias processuais básicas tanto às testemunhas como aos empregados suspeitos.

Assim, Estrada i Cuadras e Angli (2013) afirma que a intervenção da empresa na esfera privada do empregado só está autorizada quando a medida se apresentar como adequada, necessária e proporcional em sentido estrito. A investigação será adequada se a medida for idônea para atingir o fim proposto. Será necessária, por sua vez, quando a intervenção se mostrar absolutamente indispensável no caso, diante da ausência de mecanismos menos severos e igualmente eficazes. Por último, haverá proporcionalidade em sentido estrito da investigação quando as medidas adotadas se afigurarem mais vantajosas para o interesse comum do que as restrições impostas aos direitos do suspeito.

Não obstante a isso, a análise da proporcionalidade em um caso concreto deve considerar que " [...] o grado de afectación a la intimidad depende de la intensidade de la expectativa de la intimidad, que es la que em términos cuantitativos dota de contenido este derecho dentro de la empresa" (NIETO MARTÍN, 2015a, p. 247). Assim, a expectativa de intimidade do empregado que recebe o Código e Ética com cláusula genérica prevendo a possibilidade de monitoração do correio eletrônico de todos os funcionários, afigura-se completamente diversa do subordinado que é pessoalmente comunicado por seu superior sobre a fiscalização da sua caixa postal eletrônica.

A partir desses parâmetros, uma hipótese de intromissão indevida na intimidade do trabalhador ocorre quando a apuração de infrações implica na análise desavisada de a) imagens registradas pelo sistema de monitoração eletrônica, b) documentos arquivados pelo suspeito em 
seu computador de trabalho, c) histórico de acesso à rede mundial de computadores, d) caixa postal eletrônica, e) conversas telefônicas mantidas em aparelhos físicos ou móveis fornecidos pelo empregador.

Não obstante a isso, o princípio da proporcionalidade afigura-se necessário inclusive nos casos de monitoramento consentido dos meios eletrônicos de produção, porque programas de informática que registram indiscriminadamente todo conteúdo acessado pelo trabalhador em seu computador de trabalho podem ser facilmente substituídos pelo sistema de busca cega, com fiscalização sobre objetos selecionados aleatoriamente, a partir de palavras-chave relacionadas com a atividade empresarial.

Outra medida adequada para preservar direitos dos investigados consiste no registro dos depoimentos em documento escrito ou em mídia, com a data da oitiva, a qualificação do depoente e do investigador, além de referências ao procedimento interno de investigação. Durante a realização do ato, a equipe de trabalho também deve informar o objeto da investigação ao depoente, e assegurar ao investigado o exercício do direito de defesa, inclusive por meio do silêncio.

Como consequência lógica, afigura-se altamente desaconselhável a elaboração de cláusulas contratuais que obrigam o empregado a informar tudo o que sabe nas investigações corporativas, com fundamento no dever de direção do empresário sobre os atos da pessoa jurídica. Ainda que lastreado no poder de inquirir o funcionário acerca do modo de execução dos seus serviços na corporação, sabe-se que, na prática, “[...] en caso de negativa a contestar, el trabajador se encontraría en uma situación delicada, pues su falta de colaboración puede implicar que el empleador perda em él la confianza y le considere persona no idónea para desempeñar um puesto de trabajo." (NIETO MARTÍN, 2015a, p. 253).

Para evitar essas e outras situações, é válida a elaboração de um Estatuto dos Trabalhadores no âmbito da empresa assegurando alguns direitos de defesa do suspeito nas investigações internas.

A primeira garantia básica seria a de ser informado com clareza dos fatos que lhe são imputados. O segundo corresponde ao direito de consultar os elementos de informação colhidos no curso do procedimento, com preservação da confidencialidade de algumas fontes. $\mathrm{O}$ terceiro direito do investigado consiste na possibilidade de requerer diligências e de apresentar defesa escrita ou oral. $\mathrm{O}$ quarto compreende o direito à assistência jurídica durante todos os atos da investigação, e o quinto é representado pelo princípio da presunção de inocência que deve orientar todo procedimento.

Além das medidas expostas acima, o departamento de compliance também pode regulamentar a investigação corporativa tendo como parâmetro as normas previstas no Decreto 
8.420, de 18 de março de 2015, que disciplina o processo administrativo de responsabilidade - PAR na denominada Lei Anticorrupção (Lei 12.846/13).

Dadas às especificidades das investigações corporativas, é possível ajustar as regras do processo administrativo de responsabilidade ao programa de integridade empresarial determinando, em primeiro lugar, a instauração de investigação preliminar sigilosa, mediante decisão fundamentada do compliance officer. $\mathrm{Na}$ oportunidade, o oficial de cumprimento designará comissão de pelo menos dois funcionários especializados no assunto, e concederá prazo de até sessenta dias para os trabalhos, podendo tal prazo ser prorrogado, justificadamente, por igual período.

Ao final da investigação preliminar, a comissão encaminhará relatório circunstanciado ao oficial de cumprimento manifestando-se sobre a existência ou não de indícios robustos de autoria e materialidade de crime, e instruindo o documento com os elementos de informação colhidos durante os trabalhos.

Havendo indícios robustos de autoria e materialidade da prática de crime, o oficial de cumprimento designará equipe técnica para iniciar a investigação corporativa, e esta, no exercício da sua função, determinará a intimação do funcionário suspeito para, no prazo de trinta dias, apresentar defesa escrita e especificar as provas que pretende produzir.

A investigação será realizada por até cento e oitenta dias, e nesse período o suspeito poderá solicitar a produção de provas novas ou a juntada de provas consideradas, por ele, como indispensáveis para elucidação dos fatos. Os pedidos serão analisados pela equipe técnica e esta decidirá, de maneira fundamentada, sobre a inadmissibilidade de provas ilícitas, impertinentes, desnecessárias, protelatórias ou intempestivas.

Após a instrução, o investigado será intimado para apresentar defesa escrita em dez dias, sendo-lhe assegurado, em todas as fases do procedimento, o exercício da ampla defesa e do contraditório, inclusive por meio da obtenção de cópia da investigação.

Ao final da investigação, a equipe de trabalho apresentará um relatório final escrito ao departamento de compliance, descrevendo os resultados obtidos e sugerindo, de maneira motivada, as sanções disciplinares a serem aplicadas, juntamente com as medidas necessárias e suficientes para o aperfeiçoamento do programa de integridade. Em seguida a alta administração da empresa será informada sobre o fato e autorizará, conforme for o caso, a implementação de novos mecanismos de controle de riscos e a aplicação da sanção disciplinar. Na oportunidade, também determinará a rescisão contratual, o oferecimento de ações cíveis de reparação de dano ou o envio dos resultados obtidos na investigação às autoridades públicas.

Respeitadas as particularidades de cada pessoa jurídica, a adoção de tais medidas no âmbito do programa de compliance irá restringir a intervenção da empresa na esfera individual 
dos empregados, reduzindo as possibilidades de abuso no curso das investigações internas.

\section{CONCLUSÃO}

Os programas de integridade, também conhecidos como programas de compliance, surgiram no contexto da sociedade de risco como mecanismo de controle dos perigos decorrentes da atividade empresarial. Objetivando evitar a responsabilidade penal da pessoa jurídica, os programas de integridade normalmente dispõem de procedimentos internos de investigação, responsáveis por apurar infrações civis, trabalhistas, ambientais e criminais supostamente praticadas em benefício ou contra a empresa.

Após a constatação da responsabilidade de algum funcionário pelo desvio, a equipe de trabalho pode adotar medidas disciplinares internas e, quando o comportamento constituir crime, comunicar o fato às autoridades públicas para atenuar ou impedir a incriminação da pessoa jurídica. Além disso, as investigações internas permitem identificar disfunções no programa de integridade e prevenir novas infrações, aprimorando a gestão dos riscos empresariais.

Durante a apuração de ilícitos penais, no entanto, é possível ocorrer a violação de direitos das testemunhas e dos acusados envolvidos na investigação, como a devassa da intimidade e da inviolabilidade das comunicações do trabalhador.

Em razão das consequências psíquicas (estigmas, exclusão social) e jurídicas (sanções administrativas, civis, trabalhistas e penais) que podem advir das investigações, o artigo teve como objetivo abordar a necessidade de limitar a intervenção da equipe de trabalho durante as investigações internas, como forma de prevenir a imposição indevida de sanções aos empregados.

Nesse sentido, a pesquisa apontou que o departamento de compliance pode limitar o procedimento interno estabelecendo um Código de Investigação Interna com as fases da investigação e os direitos assegurados aos envolvidos no feito, elaborando um Estatuto dos Trabalhadores para reduzir a vulnerabilidade do empregado nas relações de trabalho, ou ainda adotando as diretrizes do processo administrativo de responsabilidade disciplinado no bojo da Lei Anticorrupção (Lei 12.846/13).

Para indicar o formato de elaboração dos programas de compliance, foram trazidos alguns pilares sob os quais se sustentam, com destaque para (i) a cultura de integridade empresarial, compreendido como a internalização da importância de conformar os atos ao ordenamento jurídico e o fomento tanto por meio de assessorias especializadas aos funcionários, como disponibilizando canais de denúncias de irregularidades e divulgando informativos 
com os Códigos de Ética e de Conduta, além de esclarecer as competências funcionais e eventuais responsabilidades administrativas e penais de cada; (ii) fixar claramente o objetivo geral do programa, e delimitar os objetivos específicos de cada setor, imputando facilmente aos responsáveis os riscos eventualmente criados durante o funcionamento da empresa; (iii) identificação e gestão permanente dos riscos de danos nas operações empresariais, ao inventariar quais são as implicações de determinadas infrações legais para a coletividade, adotando em seguida medidas concretas de contenção de riscos, como a seleção adequada das pessoas que irão gerenciar os riscos e a capacitação permanente dos membros da empresa; (iv) a regulamentação das competências de cada setor, conjuntamente com a atribuição de responsabilidades aos funcionários que exercem dever de vigilância; (v) o desenvolvimento de um sistema interno de comunicação que permita controlar riscos por meio da gestão de dados, onde a empresa deva ofertar aos funcionários o conhecimento atual, claro e detalhado dos riscos de danos provocados por sua atividade, disponibilizando canais fluidos e diretos de informação para esclarecimento de dúvidas e sugestões de redução de riscos, devendo o programa de integridade também impor deveres de transmissão e de consulta dessas informações aos funcionários, com o intuito de promover o funcionamento integrado e harmônico de seus setores, já que, em regra, incumbe ao oficial de compliance a função de informar a cúpula da empresa as situações de risco registradas no sistema (bottom-up) para que o órgão diretivo, em seguida, transmita essa informação aos funcionários envolvidos na atividade perigosa (topdown); por fim, (vi) o sistema de supervisão e de aplicação de sanção disciplinar no interior da empresa, pois, considerando o fato de que oficial de compliance é a pessoa responsável por desenvolver, aplicar e supervisionar o programa de integridade, constitui responsabilidade sua organizar o registro físico e virtual de toda cadeia produtiva e colacionar decisões que foram adotadas no passado para solucionar casos emblemáticos (jurisprudência corporativa).

Conforme exposto, compreendendo o processo de supervisão também o monitoramento da atuação de informantes (whistleblower) e a gestão de canais de denúncias oferecidos aos trabalhadores, o oficial de compliance ao final poderá propor o aperfeiçoamento dos mecanismos de controle de riscos, bem como aplicar medidas disciplinares aos funcionários desviantes e comunicar tal fato às autoridades públicas.

Embora não represente rol exaustivo, acredita-se que essas medidas podem reduzir a restrição indevida de direitos dos trabalhadores durante e após a instauração de investigação interna sobre crimes supostamente praticados em benefício ou prejuízo da empresa. 


\section{REFERÊNCIAS BIBLIOGRÁFICAS}

BECK, Ulrich. Sociedade de risco: rumo a uma outra modernidade. Tradução de Sebastião Nascimento. 2. ed. São Paulo: Editora 34, 2011.

BRASIL. Decreto $n^{\circ} 8.420$, de 18 de março de 2015. Regulamenta a Lei 12.846, de $1^{\circ}$ de agosto de 2013, que dispõe sobre a responsabilização administrativa de pessoas jurídicas pela prática de atos contra a administração pública, nacional ou estrangeira e dá outras providencias. Disponível em: http://www.planalto.gov.br/ccivil_03/_ato2015-2018/2015/decreto/D8420. htm. Acesso em: 06 out. 2017.

. Lei $n^{\circ} 12.846$, de $1^{\circ}$ de agosto de 2013. Dispõe sobre a responsabilização administrativa e civil de pessoas jurídicas pela prática de atos contra a administração pública, nacional ou estrangeira, e dá outras providências. Disponível em: http://www.planalto.gov.br/ ccivil_03/_ato2011-2014/2013/lei/112846.htm. Acesso em: 06 out. 2017.

BOTTINI, Pierpaolo Cruz. Crimes de perigo abstrato. 2. ed. rev. e atual. São Paulo: Revista dos Tribunais, 2010.

COCA VILA, Ivó. ¿Programa de cumplimiento como forma de autorregulación regulada? In: Criminalidad de empresa e compliance. SILVA SÁNCHEZ, Jesús-Maria (org.). Barcelona: Atelier, 2013, pp. 43-76.

ESTRADA i CUADRAS, Albert; ANGLÍ, Mariona Lloblet. Derechos de los trabalhadores y deberes del empresário: conflicto em las investigaciones empresariales internas. In: Criminalidad de empresa e compliance. SILVA SÁNCHEZ, Jesús-Maria (org.). Barcelona: Atelier, 2013, pp. 197-228.

GUIVANT, Júlia. A trajetória das análises de risco: da periferia ao centro da teoria social. In: Revista Brasileira de Informação Bibliográfica em Ciências Sociais. Rio de Janeiro, n. 46, p. 3-38, $2^{\circ}$ semestre de 1998.

KHULEN, Lothar, Cuestiones fundamentales de compliance y Derecho Penal. In: Compliance y teoria del Derecho Penal. ; PABLO MONTIEL, Juan. UERBINA 
GIMENO, Iñigo Ortiz de. Madrid: Marcial Pons, 2013, pp. 51-76

LYRA, Roberto. Crimes contra a economia popular: legislação, doutrina, jurisprudência. Rio de Janeiro: Livraria Jacinto, 1940.

MARTIN, Luis Gracia. Prolegômenos para a luta pela modernização e expansão do direito penal e para a crítica do discurso de resistência. Tradução de Érica Mendes de Carvalho. Porto Alegre: Sérgio Antonio Fabris Editor, 2005.

MARTÍN, Victor Gomez. Compliance y derechos de los trabajadores. In: PUIG, Santiago Mir; BIDASOLO, Mirentxu Corcoy; MARTÍN, Victor Gomez (org.). Responsabilidad de la empresa y compliance: programas de prevención, deteción y reacción penal. Montevideo: $\mathrm{B}$ de F., 2014, pp. 421-458.

NIETO MARTÍN, Adán. El cumplimiento normativo. In: Manual de cumplimiento penal em la empresa. (org.). Valência: Tirant lo Blanch, 2015, pp. 25-45.

. Investigaciones internas. In: Manual de cumplimiento penal em la empresa. (org.). Valência: Tirant lo Blanch, 2015a, pp. 231-270.

SIEBER, Ulrich. Programas de compliance em derecho penal de la empresa. Una nueva concepción para controlar la criminalidade económica. Tradução de Manuel A. Abanto Vásquez. In: ZAPATERO, Luis Arroyo; MARTÍN, Adán Nieto (org.). El derecho penal económico em la era compliance. Valência: Tirant Lo Blanch, 2013, pp. 63-109.

SILVA SANCHEZ, Jesús-María. Deberes de vigilância y compliance empresarial. In: KUHLEN, Lothar; MONTIEL, Juan Pablo. GIMENO, Ínigo Ortiz de Urbina. Compliance y teoria del derecho penal. Mardid: Marcial Pons, 2013, pp. 79-105.

- Teoria del delito y Derecho Penal Econômico-empresarial. In: SILVA SÁNCHEZ, Jesus-María; LLINARES, Fernando Miro (org.). La teoria del delito en la prática penal económica. Madrid: La Ley, 2013a.

PRITTWITZ, Cornelius. La posición jurídica (en especial, posición de garante) de los compliance officers. In: KUHLEN, Lothar; MONTIEL, Juan Pablo. GIMENO, Ínigo Ortiz de 
Urbina. Compliance y teoria del derecho penal. Mardid: Marcial Pons, 2013, pp. 79-105.

RAGUÉS i VALLÉS, Ramón. El fomento de las denuncias como instrumento de política criminal contra lla criminalidade corporativa: whistleblowing interno vs. Whistleblowing externo. In: PUIG, Santiago Mir; BIDASOLO, Mirentxu Corcoy; MARTíN, Victor Gomez (org.). Responsabilidad de la empresa y compliance: programas de prevención, deteción y reacción penal. Montevideo: B de F., 2014, pp. 459-486.

SANCHEZ, Juan Antonio Lascuraín. Salvar al oficial Ryan: sobre a possibilidad penal del oficial de cumplimiento. In: PUIG, Santiago Mir; BIDASOLO, Mirentxu Corcoy; MARTÍN, Victor Gomez (org.). Responsabilidad de la empresa y compliance: programas de prevención, deteción y reacción penal. Montevideo Montevideo: B de F., 2014, pp. 301-336.

SOUZA, Artur de Brito Gueiros. Programas de Compliance e a atribuição de responsabilidade individual nos crimes empresariais. In: Revista portuguesa de ciência criminal. Coimbra, ano 25, no 1 a 4, janeiro-dezembro de 2015, pp. 117-143.

\section{SOBRE OS AUTORES:}

José Rafael Fonseca de Melo é doutorando em Direito Penal pela Universidade do Estado do Rio de Janeiro (UERJ), Mestre em Direito Penal pela Universidade Federal de Pernambuco (UFPE) e Especialista em Direito Penal e Criminologia pelo Instituto de Criminologia e Políticas Criminais do Paraná (ICPC). Advogado Criminal.

Guilherme Dutra Marinho Cabral é Mestre em Direito Penal pela UERJ. Atualmente é professor de Direito Penal na Universidade Vale do Rio Doce (UNIVALE). Tem experiência na área de Direito, com ênfase em Direito Penal e Criminologia Crítica.

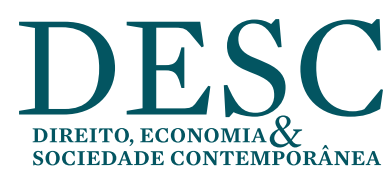

